\title{
Power Quality Improvement of AC Distribution System using 3 Phase PV Integrated UPQC with Advanced Control Strategy
}

\author{
Venkateswarlu M., Pakkiraiah B.
}

\begin{abstract}
Renewable energy sources are used to accommodate the ongoing increasing power demand. So, the integration of $P V$ system controlled by the revised $p-q$ concept which is revealed from instantaneous active reactive power concept and a suitable choice to meet the energy demand. Enormous utilization of power electronic converters deviates the quality of power. Series voltage compensation and shunt current compensation is done by the $p-q$ theory. Revised $p-q$ conceptstates the single instantaneous active power and the imaginary powers for active and reactive power compensation. This paper presents the revised $p$-q concept to generate the reference signals for integrated unified power quality conditioner (PV-UPQC-S). This proposed method enables the process of $P V-U P Q C-S$ under unbalanced voltage circumstances at the point of common coupling (PCC). This system incorporates the series voltage source converter (VSC) to control the unbalanced voltage by sharing the part of the reactive power of the load, which in turn reduces the rating of the shunt VSC. The integration of the PV system at the DC bus of UPQC serves the purpose of load sharing as well as power quality improvement to maintain the healthy grid condition. This concept is approved by simulating the proposed model in MATLAB/Simulink. The proposed model comprises of both linear and non-linear loads. The experimental results validates the perfect dynamical response of the given model.
\end{abstract}

Keywords: Custom power devices, Distributed power generation, Power conditioning, Power generation control, Power system management.

\section{INTRODUCTION}

Widespread utilization of Electrical energy leads to innovations of new approaches for electrical energy generation from Renewable energy sources. Energy generated by the conventional energy sources leads to atmospheric pollution and reduction in the available resources. Whereas, energy generated by non-conventional sources is clean and efficient. Non-linear loads like diode bridge rectifiers induces harmonics into the system. DG controlled p-q theory is used for harmonic conditioning [1]. Reference current signals for voltage source converter are generated by the different control methodologies like Constant instantaneous power method, synchronous current control method, fryze current control method and

Revised Manuscript Received on September 22, 2019

* Correspondence Author

Venkateswarlu M.*, Research Scholar, Department of EEE, Koneru Lakshmaiah Education Foundation, Vaddeswaram, Guntur, A. P., 522 502, India. e-mails:malapativenkateswarlu9@gmail.com

Pakkiraiah B., Associate Professor, Member IEEE, ISTE, IAENG, Department of EEE, Gokaraju Rangaraju Institute of Engineering and Technology-Autonomous, Bachupally, Hyderabad, Telangana State, 500090, India.pakki1988@gmail.com synchronous reference frame methods are explained and compared in view of harmonic reduction [2]. Usually p-q theory has a constraint for non-sinusoidal and/or unbalanced supply. Modified p-q theory developed for this particular kind of supply. The formulation of the modified $p-q$ theory was explained and experimentally verified. More over these results are compared with the original instantaneous active reactive power theory [3]. Modified p-q theory is sophisticated control methodology over the synchronous reference frame theory. Mathematical modelling is done for a $3-\varnothing, 3-$ wire and $3-\varnothing, 4-$ wire systems [4]. A control scheme is developed for PV integrated $1-\varnothing$ A.C. system by using the modified $\mathrm{p}-\mathrm{q}$ theory. A maximum power point tracking method is applied to track the maximum power from PV system. Phase locked loop system is used for phase detection in both $1-\emptyset$ as well as $3-\emptyset$ systems [5,6]. New methodology was proposed for $3-\emptyset$, 4-wire distribution system with power quality improvement while integrating the PV system. This concept was constructed with PSCAD/DMTDC environment [7].

UPQC is used to enrich the power quality in distribution system. An overview of UPQC in view of their usage, function and tasks are given. All these discussed varieties are classified based upon their functionalities [8]. UPQC is formed with the series voltage source converter in order to compensate the effect of non-linear loads at the distribution systems. It controls the voltage imbalance and reduce the harmonic content in the supply system which is effected by the non-linear loads [9]. A sliding mode controller incorporated with instantaneous active reactive power theory. This new approach will give quick dynamic response, suitable for unbalanced networks and control the sag/swell in supply voltage [10]. DC-link voltage variation is the prime task in UPQC device and this is accomplished by the PI controller. This same function is accomplished by the adaptive neuro fuzzy inference system (ANFIS) which is superior to the conventional technique [11]. The extensive research over different methodologies for creating the reference current signals to the voltage source converter provides crystal clear idea of the power quality concept in the incorporation of the renewable energy sources.

\section{BASIC STRUCTURE OF PV-UPQC-S:}

The proposed model for PV-UPQC-S is illustrated in Fig. 1. The main functional components of the model are the Shunt VSC and Series VSC. Photovoltaic system is linkedover a reverse blocking diode to the DC-bus. The shunt VSC attached to the PCC over

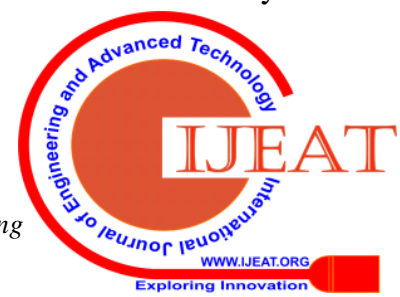


an interfacing inductor. The series VSC linked to the same terminals of shunt VSC over a common DC-bus. The series VSC is linked through an interfacing inductor and a series injection transformer. Ripple filter constitutes a series RC circuit is connected across the injection transformer to filter out the VSC harmonics. Anarrangement of Linear and non-linear loads fed by the source and PV system.

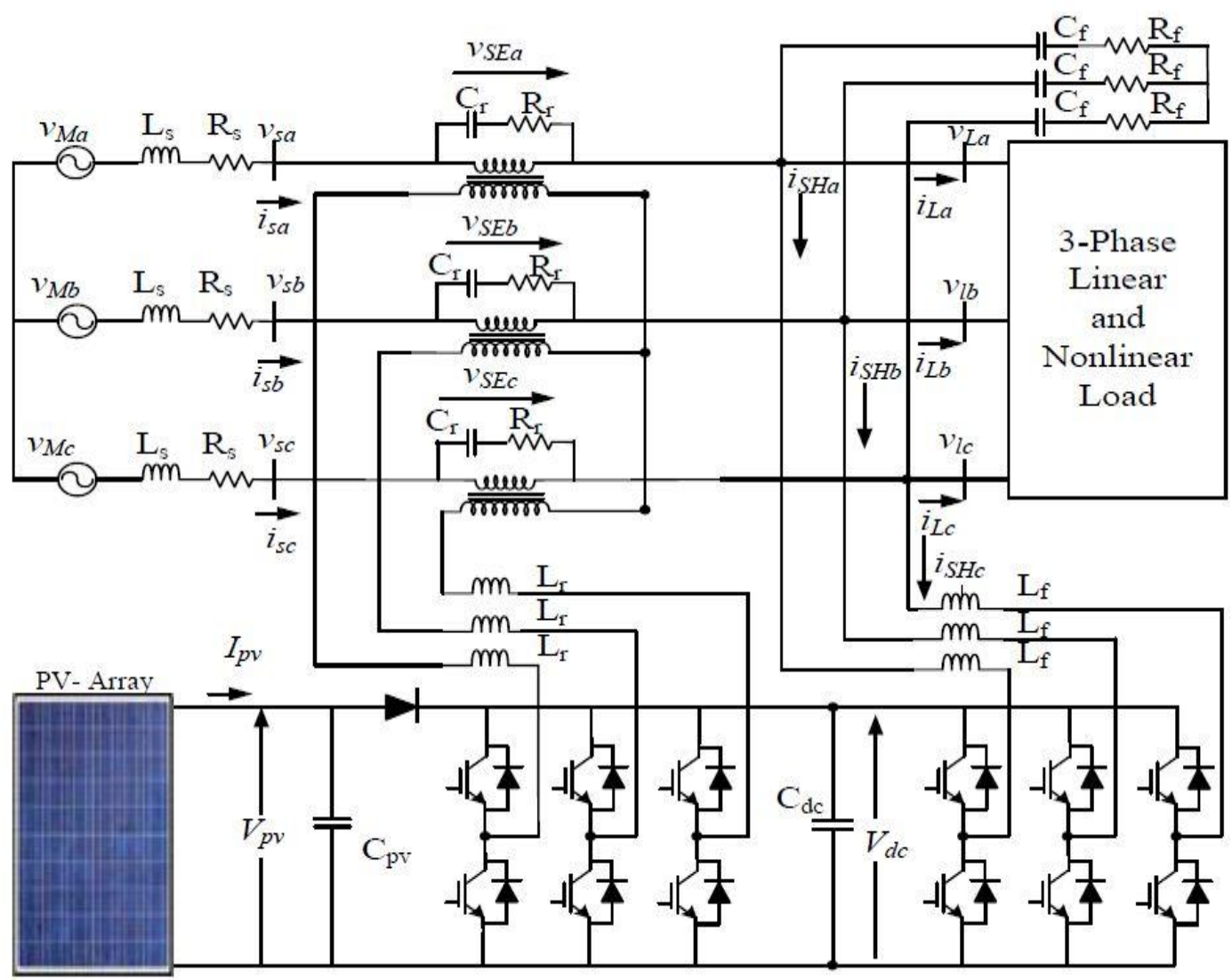

Fig. 1. Basic Structure of Proposed System

$\mathrm{V}_{\mathrm{sa}}, \mathrm{V}_{\mathrm{sb}}, \mathrm{V}_{\mathrm{sc}}$ are the $3-\varnothing$ voltages of source supply and $\mathrm{i}_{\mathrm{sa}}$, $i_{\mathrm{sb}}, \mathrm{i}_{\mathrm{sc}}$ are the $3-\emptyset$ source currents. The power flow and the reactive power compensation are clearly explained with the help of a phasor diagram presented in Fig. 2. Consider the load voltage before compensation $\left(\mathrm{V}_{\mathrm{L} 1}\right)$ is taken as a reference Phasor. The phase angle ' $\varnothing$ ' is the angle between $\mathrm{V}_{\mathrm{L} 1}$ and $\mathrm{I}_{\mathrm{L} 1}$. Voltage at the PCC $\left(\mathrm{V}_{\mathrm{S} 1}\right)$ is in phase with $\mathrm{V}_{\mathrm{L} 1}$. PV voltage $\mathrm{V}_{\mathrm{PV}}$ and current $\mathrm{I}_{\mathrm{PV}}$ are the real power elements injects real power via shunt VSC. $\mathrm{I}_{\mathrm{SH} 1}$ is the shunt VSC current formerly series VSC injection. It is the summation of load reactive current and PV current. $\mathrm{V}_{\mathrm{L} 2}$ is the load voltage when a portion of the load is taken by series VSC. The load voltage is shifted with the injection of voltage $\mathrm{V}_{\mathrm{SE}}$. The shunt VSC current is reduced to $\mathrm{V}_{\mathrm{SH}_{2} \mathrm{O}}$ wing to power angle $(\delta)$. Whereas the grid current remains same $\left(\mathrm{I}_{\mathrm{S} 1}=\mathrm{I}_{\mathrm{S} 2}=\mathrm{I}_{\mathrm{S}}\right)$

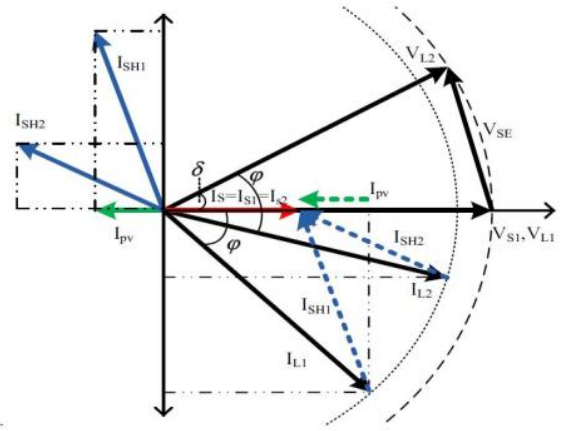

Fig. 2. Phasor representation of PV-UPQC-S

\section{REVISED P-Q CONCEPT CONTROL STRATEGY}

Regulation of PV-UPQC-S consists of four basic blocks. Generalized cascaded delay signal cancellation block (GCDSC), load power measurement block, series VSC control block and shunt VSC control block.
Delay signal cancellation block implementation is revealed in Fig. 3 (a). $V_{\alpha}, V_{\beta}$ is given to delay block with $M$ delay samples with a delay factor of N. Five delay signal blocks with different delay features are cascaded as shown in Fig. 3 (b). It prevents the un necessary complexity in the system.

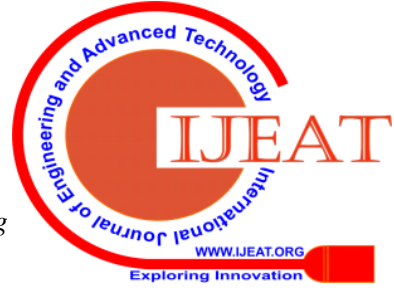




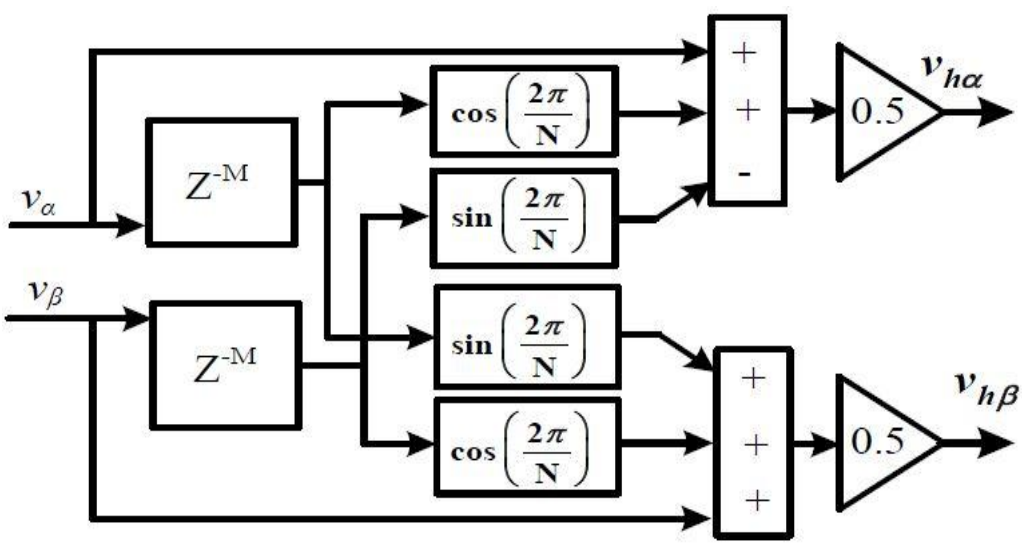

(a) Block $-\mathrm{N}$ control block of DSC

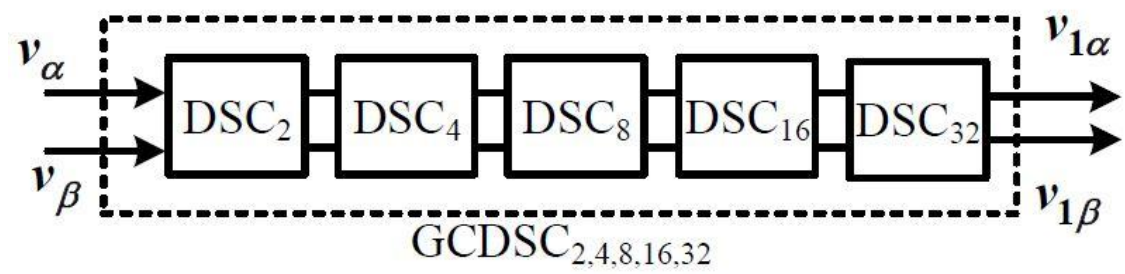

(b) GCDSC control Block

Fig. 3 GCDSC Cancellation Block

Power calculation block uses $\mathrm{p}-\mathrm{q}$ concept estimates using clarke's transformation. $\mathrm{p}_{\mathrm{L}}$ and $\mathrm{q}_{\mathrm{L}}$ are calculated from instantaneous active power $\left(\mathrm{P}_{\mathrm{L}}\right)$ and reactive power $\left(\mathrm{Q}_{\mathrm{L}}\right)$. Fig. 4 gives the illustration of load power calculations. The load the transformed voltages and currents. Low pass filter voltages and currents are converted into $\mathrm{V}_{\mathrm{L} \alpha}, \mathrm{V}_{\mathrm{L} \beta}, \mathrm{i}_{\mathrm{L} \alpha}$ and $\mathrm{i}_{\mathrm{L} \beta}$ isolates the ripples in active and reactive power.

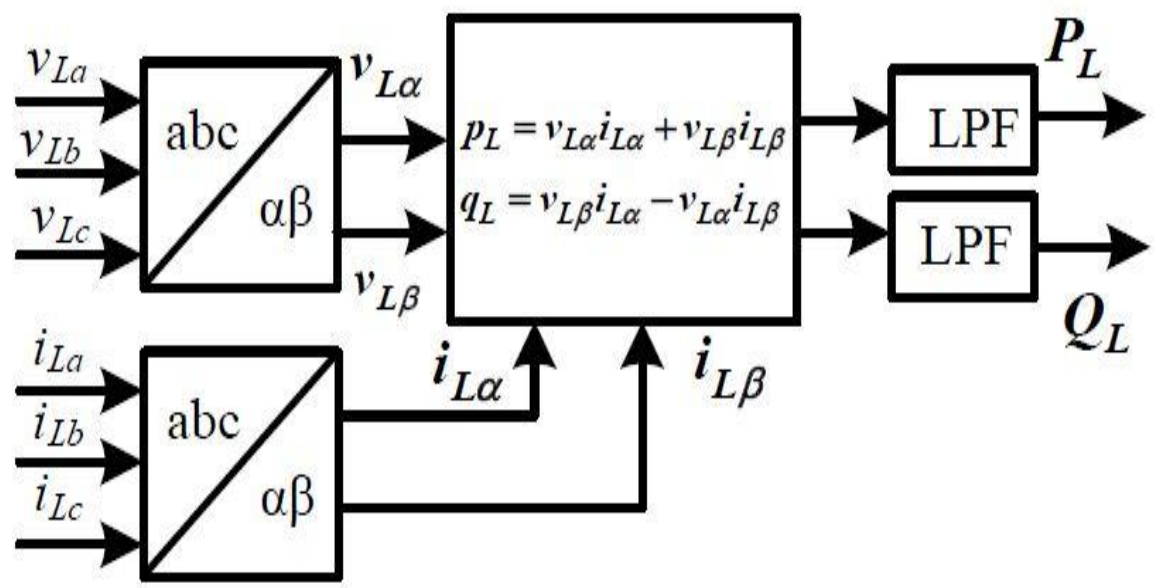

Fig. 4. Load power calculation block

The diagrammatic illustration of shunt VSC is shown in Fig. 5. The shunt VSC improves the quality of power by mitigating the harmonics, maintaining the good power factor and shares the load which is obtained from PV system. MPPT algorithm gives DC-bus reference value. Perturb and observation ( $\mathrm{P} \& \mathrm{O}$ ) algorithm is used because of its superiority over the other algorithms. DC-bus voltage is equatedby way of reference DC-bus voltage obtained from MPPT technique. Error between these two gives to the PI controller which contributes the power loss section. The source voltages $\mathrm{V}_{\mathrm{sa}}, \mathrm{V}_{\mathrm{sb}}, \mathrm{V}_{\mathrm{sc}}$ are transformed ito $\mathrm{V}_{\mathrm{s} \alpha}, \mathrm{V}_{\mathrm{s} \beta}$ by using clarke's transformation. The values of $\mathrm{V}_{\mathrm{s} 1 \alpha}, \mathrm{V}_{\mathrm{s} 1 \beta}$ are attained from GCDSC block. The rated grid current are obtained from $\mathrm{P}_{\text {ref }}$ and $\mathrm{V}_{\text {sfla }}, \mathrm{V}_{\mathrm{sfl} \beta}$. These signals are altered into abc by using inverse clarke's transformation. Hysteresis current controller equates the reference signals $i_{\mathrm{sa}}^{*}, \mathrm{i}_{\mathrm{sb}}^{*}, \mathrm{i}_{\mathrm{sc}}^{*}$ with $i_{\mathrm{sa}}, i_{\mathrm{sb}}, \mathrm{i}_{\mathrm{sc}}$ to produce gating pulses for shunt VSC. 



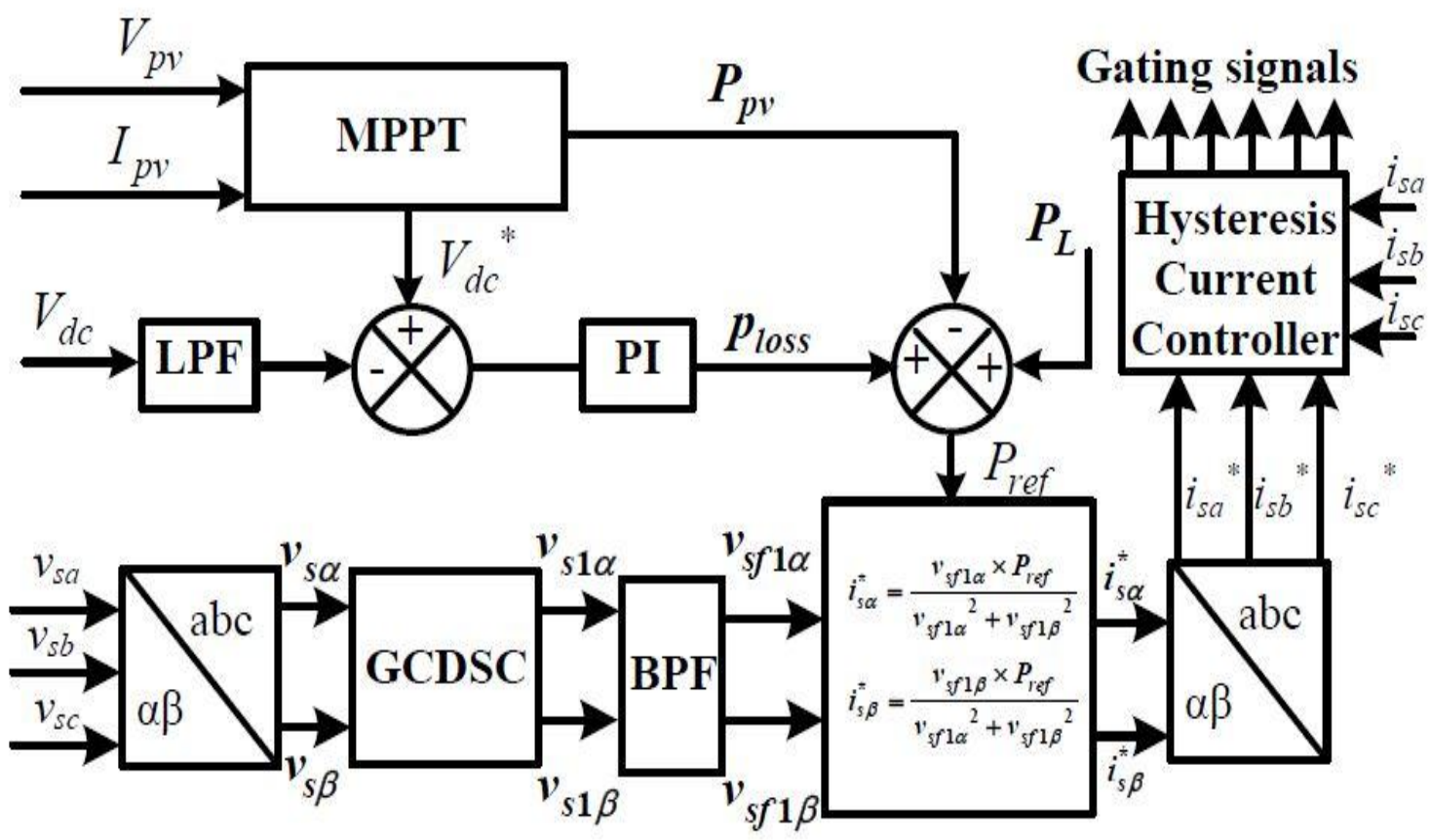

Fig. 5. Control structure of shunt VSC

The regulatorillustration of the series VSC is revealed in Fig. 6. Series VSC takes aportion of the load reactive power. It also controls the voltage sags/swells. Power angle $\delta$ will be altered according to the condition of voltage. Fundamental $\mathrm{V}_{\mathrm{s}}$ and $\theta$ are calculated from $\mathrm{V}_{\text {sfl } \alpha}$, $\mathrm{V}_{\text {sf } 1 \beta}$. Reactive power is injected under voltage sag/swell conditions by the series VSC. The calculated reference and the load voltages are given to the pulse width modulated controller. The PWM controller will produce gating signals for the series VSC.

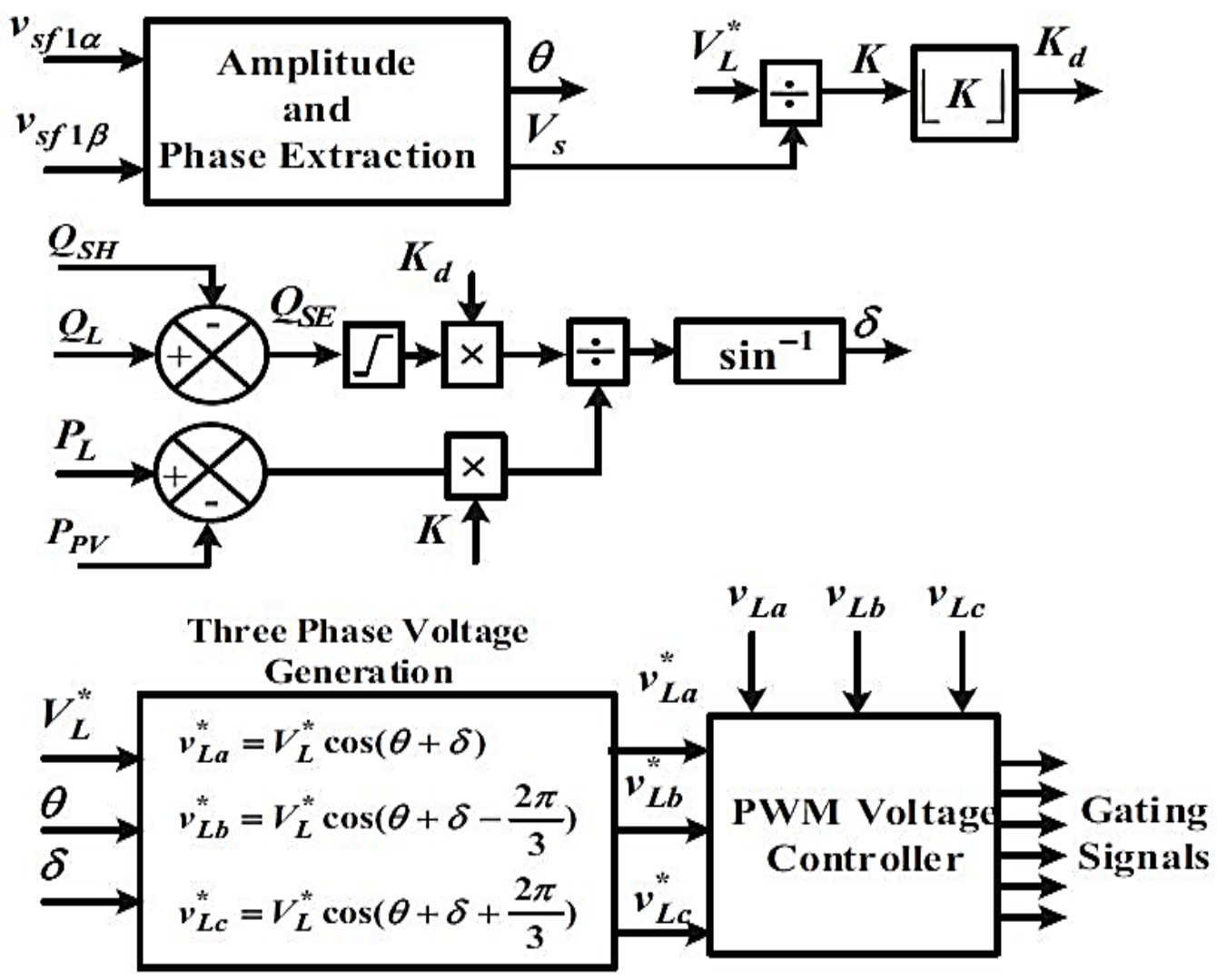

Fig. 6. Regulator structure of series VSC 
Power Quality Improvement of AC Distribution System using 3 Phase PV Integrated UPQC with Advanced Control Strategy

\section{SIMULATION RESULTS AND ANALYSIS}

The proposed model is constructed in MATLAB/Simulink using Sim power systems block set. The system is evaluated for three different conditions which are (i) Fluctuations in voltage at PCC, (ii) non-uniform irradiance and (iii) Unbalanced load conditions. The three conditions are explained along with the help of simulation results.

\section{A. Fluctuations in voltage at PCC}

The outputs of PV-UPQC-S under fluctuation in voltage is displayed in Fig. 7. There is no change in solar irradiation.

Various signals of phase 'a' are shown. Only one phase is taken into attention for clarity purpose. There is a voltage sag at time $t=0.65 \mathrm{~s}$ along with ripple content and voltage swell at time $t=0.75 \mathrm{~s}$. The load voltage shows a sinusoidal waveform even though there is a disturbance in the source voltage and the $\mathrm{V}_{\mathrm{dc}}$ is controlled. The variations and harmonic distortion can also been observed in source current and load current. A share of the Q is taken by the series VSC.
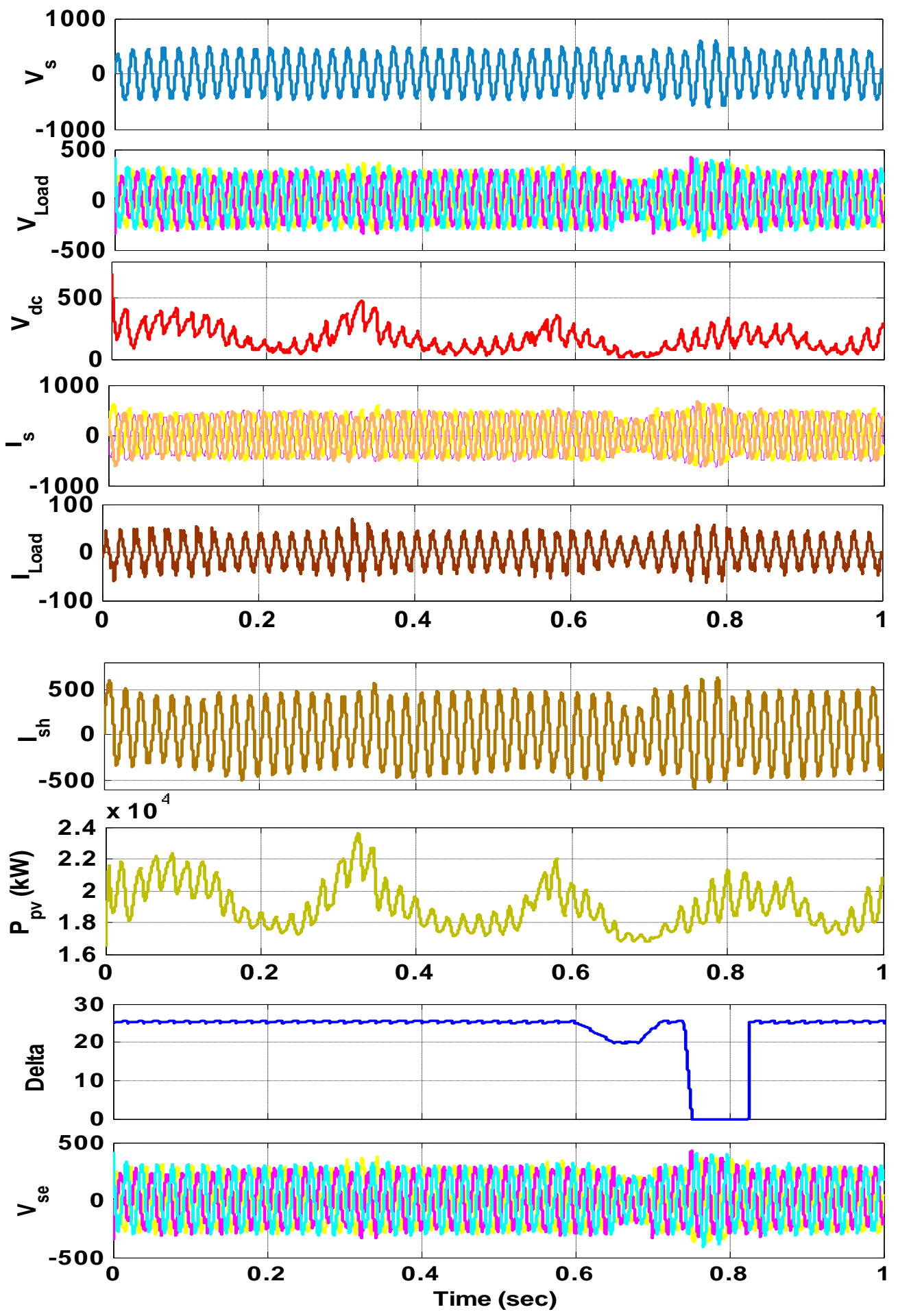

Fig. 7. Performance signals at PCC due to Voltage fluctuations 


\section{B. Under non-uniform irradiation condition}

The signals under non-uniform irradiation is revealed in Fig. 8. There is a change in solar irradiation from $0.95 \mathrm{~s}$ to $1 \mathrm{~s}$. The source, load and DC voltage are Up held fixed regardless of non-uniform irradiation. As seen in the waveform, source current increase as a result of decrement in solar power output due to decrement in solar irradiation. Load current and shunt VSC current of phase (a) are given for consideration. There is also a considerable change in series VSC voltage.
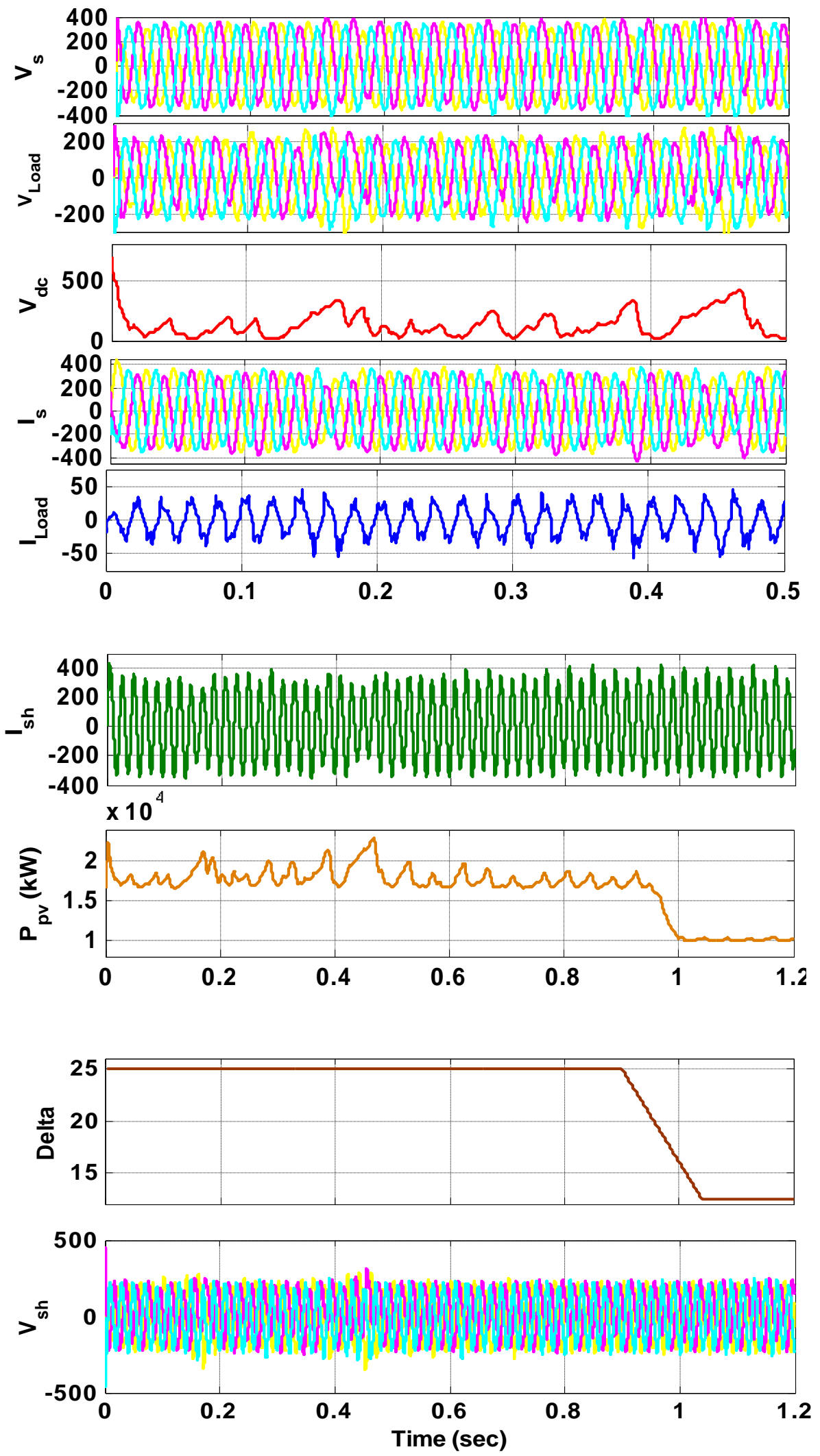

Fig. 8. Performance signals under non-uniform irradiation 
Power Quality Improvement of AC Distribution System using 3 Phase PV Integrated UPQC with Advanced Control Strategy

C. Under unbalanced load condition

The outcomes under unbalanced load conditions are displayed in Fig. 9. A load in phase ' $b$ ' is disconnected at time $\mathrm{t}=0.51 \mathrm{~s}$ for the condition of unbalance. Grid maintains a balanced supply voltage even under the unbalanced load condition. The shunt VSC pay off the reactive power. The
DC power output from PV system is maintained constant. So, the proposed modified $\mathrm{p}-\mathrm{q}$ theory applied to PV integrated distribution system performs well under various disturbance in voltage at PCC, non-uniform irradiance and unbalanced conditions.
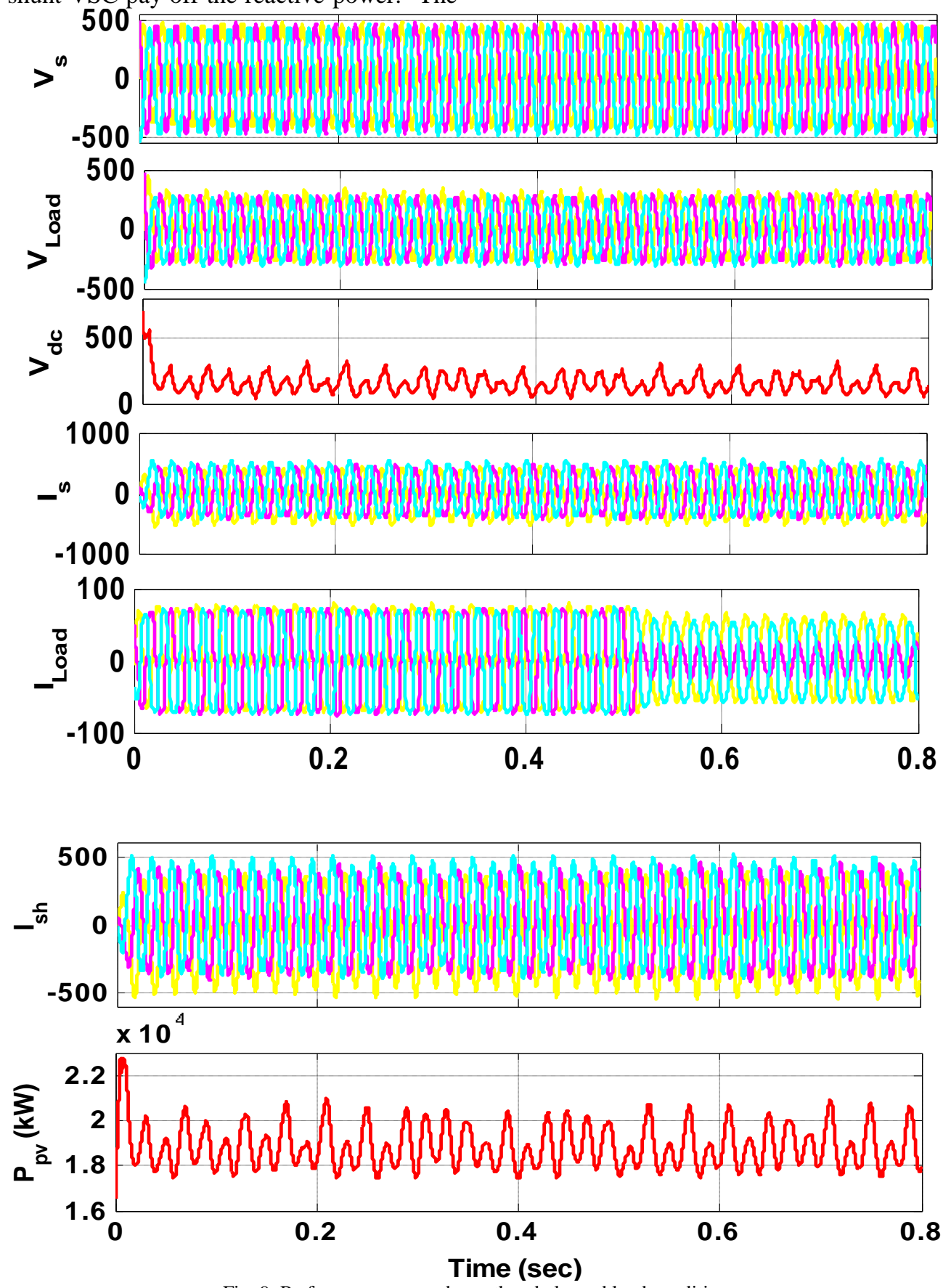

Fig. 9. Performance curves beneath unbalanced load condition

\section{CONCLUSION}

The essence of promoting the clean energy in place of conventional energy is performed by integrating the photovoltaic system to the utility grid with unified power quality conditioner PV-UPQC-S. This modified controller proves that it is also suitable for non-sinusoidal and unbalanced supply systems. A different cases of unbalanced and distorted voltages are effectively controlled and maintain the quality of power under any kinds of loads connected at the end user level. Voltage dip of $170 \mathrm{~V}$ and voltage swell of 260
$\mathrm{V}$ is brought back to normal operating voltage value of $220 \mathrm{~V}$. Implementation of maximum power point tracking assures approximately $99 \%$ of the power even in the non-uniform irradiation condition. This system is capable of dealing the voltage disturbances as well as non-uniform irradiation. Finally, promotion of clean energy in place of conventional energy is the futuristic implementation of the energy sector. 


\section{REFERENCES}

1. Kranthi Kumar. V. and Pakkiraiah B., "Green Energy Integration to Utility grid with Power Quality Improvement by using APF", First International Conference on Advances in Electrical and Computer Technologies 2019, Coimbatore, pp. 158-167, Apr. 2019.

2. Kranthi Kumar. V. and Pakkiraiah B., "Development of Control techniques for SAPF for Power Quality Enhancement", Journal of Advanced Research in Dynamical \& Control System, vol.10, no.9-Special Issue, pp. 1900-1907, July 2018.

3. M. Ranjbar and A. Jalilian "Modified Single-Phase Instantaneous Reactive Power Theory:Formulation, Simulation, and Experimental Verification", First Power Quality Conference, Tehran, Iran, Sept. 2010 .

4. Kumar A., Anjana P., Tiwari H. and Gupta V., "Modified P-Q Technique to Mitigate Power Quality Problems in Distribution System", First International Conference on Power Electronics Intelligent Control and Energy Systems, Delhi, India, July 2016.

5. K. Kelesidis, G. Adamidis and G. Tsengenes, "Investigation of a control scheme based on modified $\mathrm{p}-\mathrm{q}$ theory for single phase single stage grid connected PV system", International Conference on Clean Electrical Power, Ischia, Italy, June 2011.

6. Babu, T. Vandana, T. Satyanarayana Murthy, and B. Sivaiah. "Detecting unusual customer consumption profiles in power distribution systems-APSPDCL." 2013 IEEE International Conference on Computational Intelligence and Computing Research. IEEE, 2013.

7. S. Khani, L. Mohammadian and S.H. Hosseini "Modified p-q Theory Applied to Flexible Photovoltaic Systems at the 3-Phase 4-Wire Distribution Grids", Proceedings of $17^{\text {th }}$ Conference on Electrical Power Distribution, Tehran, Iran, May 2012.

8. Nurzaman, Tri Susilowati, and Arif Dian Wahyudi. "Drug Inventory Information System In Asy-Syifaa Yukum Jaya Islamic Hospital." International Journal of Communication and Computer Technologies 7.2 (2019), 27-31. Print. doi:10.31838/ijccts/07.02.07

9. Sreedhar Ranjan Das, Bibhuti Bhusanpanigrahi, Manojkumar.Pani. "A Review on compatibility of "Sucralfate" in bi layer floating tablet for treatment of ulcer in pregnancy.." International Journal of $\begin{array}{llll}\text { Pharmacy Research \& Technology } 10.1 \quad \text { (2020), 12-16. } & \end{array}$ Print. doi:10.31838/ijprt/10.01.04

10. Rao, B. Venkateswara, et al. "Optimal power flow by Newton method for reduction of operating cost with SVC models." 2009 International Conference on Advances in Computing, Control, and Telecommunication Technologies. IEEE, 2009. 